Research Article

\title{
Eco-Efficiency of Industrial Investment and Its Influencing Factors in China Based on a New SeUo-SBM-DEA Model and Tobit Regression
}

\author{
Chuanjin Zhu $\mathbb{D}^{1},{ }^{1}$ Nan Zhu, ${ }^{2}$ and Wasi Ul Hassan Shan ${ }^{1}$ \\ ${ }^{1}$ School of Statistics, Southwestern University of Finance and Economics, Chengdu, China \\ ${ }^{2}$ Western Business School, Southwestern University of Finance and Economics, Chengdu, China \\ Correspondence should be addressed to Chuanjin Zhu; chuanjinzhu@smail.swufe.edu.cn
}

Received 24 May 2020; Revised 23 November 2020; Accepted 13 March 2021; Published 22 March 2021

Academic Editor: Mehmet Cunkas

Copyright ( 92021 Chuanjin Zhu et al. This is an open access article distributed under the Creative Commons Attribution License, which permits unrestricted use, distribution, and reproduction in any medium, provided the original work is properly cited.

\begin{abstract}
Nowadays, eco-efficiency is one of the most widely used comprehensive indicators in many fields and sectors. Understanding ecoefficiency is of great significance to implement sustainable socioeconomic development for decision makers. To assess the comprehensive performance of industrial investment, the eco-efficiency of industrial investment (EEII) is constructed under the comprehensive perspective of economic benefits, energy consumption, and environmental impact in this paper. Then, a new superefficient undesirable-output slack-based measure DEA (SeUo-SBM-DEA) model is proposed and applied to assess the EEII of 30 provinces in China from 2015 to 2017, and its influencing factors are analyzed using the Tobit regression. The empirical results show the following: (1) the eco-efficiency of China's industrial investment is generally low (0.613), and there exists a significant regional disparity; namely, the average value of EEII was the highest in the eastern regions (0.838), followed by the central regions (0.6) and western regions (0.397). (2) R\&D expenditure, economic development level, and foreign direct investment all had a significant positive effect on the eco-efficiency of industrial investment, while investment in treatment of industrial pollution sources and total education funds all had a significant negative effect. Finally, this paper puts forward some suggestions to promote sustainable development of industrial investment based on our findings.
\end{abstract}

\section{Introduction}

China's industrial development research report (2019) published by China Academy of Information and Communication Technology (CAICT) comprehensively shows that China's industrial development has made remarkable achievements in the past 40 years from the reform and opening [1]. From 1978 to 2018, the average annual growth rate of all industrial added values is $11 \%$, and the output of more than 200 industrial products is ranked first in the world. In 2018, the innovation capabilities of advanced industries such as aerospace, information, and communication have been continuously improved, the industrial layout has been more optimized and coordinated, and the level of opening has been continuously improved. The report shows that China's industry should construct a policy evaluation system of high-quality industrial development as soon as possible so as to achieve sustainable industrial development and eventually realize the transformation from a big manufacturing country to a powerful manufacturing country.

However, China's industrial development is more and more relied on energy and resource inputs and expansion in production due to the extensive development mode with high-input, high-consumption, high-pollution, and lowtechnology in the past few decades, which has led to severe developmental damage [2]. For instance, the industrial investment (i.e., industrial fixed asset investment, which plays an important role in promoting economic growth, industrialization, and improving the competitiveness of enterprises), regarded as an important determinant of sustainable development of Chinese industry, accounts for an increasing 
proportion of GPD year by year, but the promotion effect of industrial investment on GDP growth is not significant. Figure 1 intuitively reflects the tendency of the proportion of China's industrial investment in GDP and its promotion effect on GDP growth since 2001 (note: the data are from the website of the National Bureau of Statistics of China, calculation method with reference to [3]), and the disparity between them is very obvious and has a tendency to expand gradually, which indicates that the actual performance and the sustainability of China's industrial investment is low. Sustainable industrial development is of great significance to sustainable socioeconomic growth, and relevant researches have gradually attracted more and more attention from many scholars. For instance, Ferrara et al. [4] developed a distributed time delay energy model under the assumption of continuously distributed time delays for implementing sustainable economic growth, and in [5], they further examined the consequences of including distributed delays in an energy model by using stability and Hopf bifurcation analysis.

In 2007, the Chinese government puts forward the strategy of ecological civilization for the first time, and the 13th Five-Year Plan (2016-2020) emphasized the unswerving implementation of the strategy [6]. Meanwhile, the China's Industrial Green Development Plan (2016-2020) also proposed a coordinated development strategy for green industry [7]. To promote sustainable socioeconomic and industrial development in the future, it is of great practical significance to scientifically and effectively assess the comprehensive performance of industrial investment and find the reasons that lead to inefficiency. However, nowadays, there are relatively lack of academic research studies on assessing the efficiency of industrial investment in China, and only the ICOR (i.e., incremental capital-output ratio) value is the common method to measure the performance of industrial investment from the perspective of single input (i.e., industrial fixed asset investment) and single output (i.e., industrial added value), so the measurement results cannot fully reflect the comprehensive efficiency of industrial investment, and more information about ICOR can be seen in $[8,9]$. Since the authors in [10] proposed the concept of eco-efficiency, the eco-efficiency is now becoming one of the most widely used comprehensive indicators in many fields and sectors $[2,11]$ so as to assess the sustainable socioeconomic development level, and thus, the eco-efficiency has gradually attracted more and more attention from many scholars. The eco-efficiency refers to maximizing economic outputs with minimal use of natural resources and environmental degradation according to [12]. Some scholars have already studied the regional and industrial eco-efficiency in China. Zhang et al. [13] constructed the pattern of eco-efficiency for regional industrial systems using real data of 30 provinces in China. Huang et al. [14] proposed an extended data envelopment analysis (DEA) model (i.e., GB-US-SBM model) to investigate the dynamics of regional eco-efficiency in China from 2000 to 2010. Integratively considering the economy, resources, and environment, Zhang et al. [6] employed a three-stage
DEA model to assess the industrial eco-efficiency of 30 provinces in China. Fan et al. [15] measured and ranked the eco-efficiency level of 40 China's industrial parks in 2012 using the indicators relevant to resources, economy, and environment and found that the different industrial parks existed a significant regional disparity. Based on geographical position and the economic development level, the abovementioned researches generally divided China into the eastern, central, and western regions and got the similar result: the average eco-efficiency was the highest in the eastern regions, followed by the central regions and western regions, and the eco-efficiency in the eastern regions also embraced a more rapid growth.

Nowadays, the industrial investment, regarded as an important determinant of sustainable development of industry, has not got sufficient attention on its eco-efficiency from scholars, and there is even no research on the eco-efficiency of China's industrial investment. Consequently, this paper attempts to conduct the ecoefficiency of industrial investment (EEII) under the comprehensive perspective of economic benefits, energy consumption, and environmental impact based on previous studies and employs an application to 30 provinces in China. Due to the continuous development of industrial sector in China, it can be expected that it will cause tremendous pressures on resources and the environment in the future, so promoting the improvement of the EEII can be a starting point for the coordinated development of China's economic and environmental goals. According to the preceding review of previous researches [16], many scholars attempted to measure the eco-efficiency using DEA models along with observing its dynamics and determinants. However, the classical DEA models have their own shortcomings, which cannot be used to directly measure the EEII at an industrial level [2]. Therefore, a new superefficient undesirable-output slack-based measure DEA (SeUo-SBM-DEA) model is proposed according to the aims and features of the EEII conducted in this paper (more details can be seen in Section 3). Then, the SeUo-SBM-DEA model is applied to assess the EEII of 30 provinces in China from 2015 to 2017, and the Kruskal-Wallis rank test is used to test whether the assessment results are statistically significant. Finally, the influencing factors of the EEII are analyzed using the Tobit regression, and some policy recommendations are put forward for sustainable development of industrial investment.

The rest of this paper is organized as follows. Researches on the eco-efficiency are reviewed in Section 2. The classical DEA models and its development and Tobit regression model are introduced, respectively, in Section 3, and a new SeUo-SBM-DEA model is proposed in this section. Empirical research and results analysis on the EEII in China is discussed in Section 4, and the Kruskal-Wallis rank test is used to test whether the main empirical conclusions are statistically significant in this section. The influencing factors of the EEII are analyzed using Tobit regression in Section 5. Finally, Section 6 gives the conclusions of this paper and puts forward some policy implications based on our findings. 


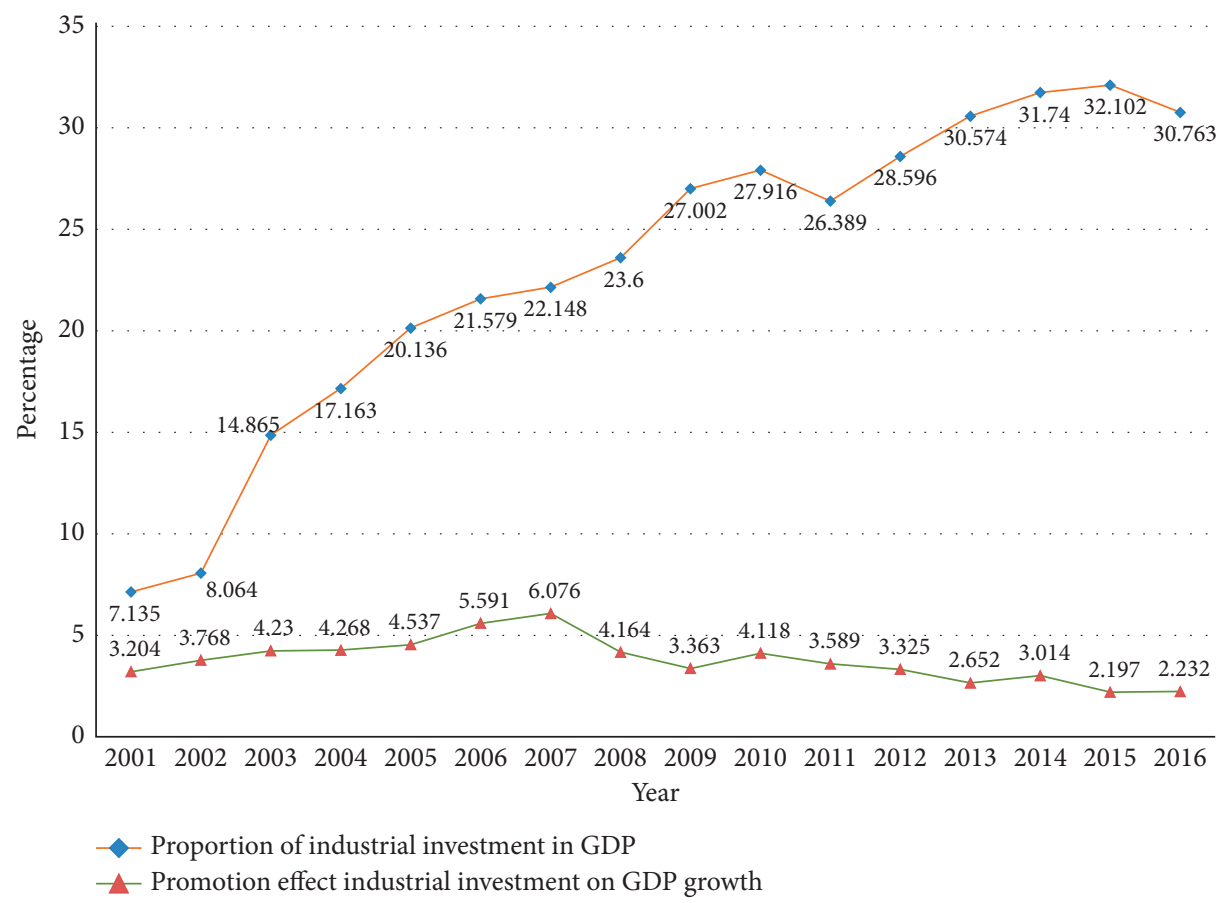

Figure 1: Proportion of industrial investment in GDP and its promotion effect on GDP growth since 2001.

\section{Literature Review}

Based on the neoclassical theory [17], the marginal efficiency of capital is equal to the ratio of the marginal increment of output to the marginal increment of capital under the condition of the same labor input. Therefore, investment efficiency is often measured in the existing literature by ICOR value. Based on this definition, the marginal productivity of capital is equal to the marginal production of capital stocks, namely, the ratio of the increment of output to the change in capital stock $(\mathrm{d} y / \mathrm{d} k)$. Meanwhile, the change in capital stock $\mathrm{d} k$ is equal to the investment flow $I$, so the efficiency of industrial investment can be measured as follows: let the marginal productivity of capital use the ratio of the increment of industrial added value $y$ to the investment $(\mathrm{d} y / I)$, and then the marginal capital-output ratio is equal to the reciprocal of the marginal productivity of capital. The formula of ICOR can be written as follows:

$$
\mathrm{ICOR}=\frac{I}{\mathrm{~d} y} .
$$

According to the definition of ICOR value, the higher the ICOR value, the lower the industrial investment efficiency. Due to the lack of academic studies on assessing the performance of industrial investment, the IOCR method is commonly used for empirical analysis by some scholars, and the relevant studies can be seen in $[8,9]$. However, the ICOR value only considers the single input (i.e., industrial fixed asset investment) and single output (i.e., industrial added value), neither considering the consumption of energy and other resources nor considering the environmental pollutants (such as waste water, waste gas, and solid waste) generated in the process of modern industrial production, so the ICOR value can only reflect the economic benefits of industrial investment, and it can not fully reflect the actual efficiency of industrial investment from the comprehensive perspective. There is no doubt that ignoring resources consumption and environmental pollution of industrial investment will not be conducive to the sustainable development of industrial sector.

Therefore, the DEA method, which has been widely used in many fields for assessing efficiency of decision-making units (DMUs) in order to improve organizational performance in private and public sectors (such as government agencies, airlines, hospitals, financial institutions, and manufacturing companies), is introduced to replace the ICOR method in this paper. It is universally acknowledged that based on Farrell's original work [18], DEA is a frontier analysis approach to efficiency measurement of DMUs with multi-inputs and multioutputs by using a linear programming methodology developed by Charnes et al. in 1978 [19]. Since then, many new methods and applications with more variables and more complicated models have been introduced, examples of models and applications of DEA can be seen in [20-22], and more information can be seen in [16] for a full bibliography of DEA.

The DEA method does not have to set the weights of the input and output variables and the form of production function, especially when the number of samples is few, and the research problem is multi-inputs and multioutputs, which has a great advantage. Hence, the DEA model has been widely used in research studies on assessing the efficiency of investment, such as efficiency of infrastructure investment $[23,24]$, efficiency of government fiscal investment [25], and efficiency of environmental protection investment $[26,27]$. In addition, many scholars extended DEA 
model from different aspects to evaluate the comprehensive efficiency of DMUs under specific circumstances. For example, the eco-efficiency, which is one of the most widely used comprehensive indicators in many fields and sectors, is examined through the development model of DEA in many previous studies under the comprehensive perspective of economy, resources, and environment, and the relevant studies can be seen in $[2,6,11,13-15]$. Consequently, we consider using the concept of eco-efficiency to assess the performance of industrial investment by integratively considering the relationships of economy, resources, and environment, and it is named as EEII (i.e., eco-efficiency of industrial investment) in this paper. Due to the shortcomings of classical DEA models, it cannot be used to directly measure the EEII from the comprehensive perspective. Therefore, a new superefficient undesirable-output slackbased measure DEA (SeUo-SBM-DEA) model is proposed (more details can be seen in Section 3).

The EEII assessed by the SeUo-SBM-DEA model is not only affected by the input-output indicators but also by many external factors. Therefore, the impact of these external factors on the EEII needs to be analyzed, thereby putting forward the corresponding suggestions. This paper employs the truncated regression method Tobit regression model to analyze the influencing factors of the EEII. The Tobit regression model is used because the EEII value computed by a new SeUo-SBMDEA model belongs to the truncated data. For such a situation in which multiple samples become a certain limit value within a specific range, the general regression method can not explain the difference in properties between the limit value and the nonlimiting observation value to ensure the consistency of the estimates [28]. Hence, the Tobit regression model is often used in combination with the DEA model, which is called a DEATobit two-stage method (i.e., the DEA model is used to assess the efficiency of DMUs in the first stage, and the Tobit regression model is used to analyze its influencing factors in the second stage). For example, Liu et al. [29] employed a DEATobit two-stage model to measure the coastal tourism ecoefficiency of 53 Chinese coastal cities and its influencing factors in 2003-2013. Wu et al. [30] proposed an improved DEA-Tobit two-stage model to measure the eco-efficiency of 58 China's coal-fired power plants and analyze the direct external factors of the eco-efficiency. Zhu et al. [31] proposed an extended DEA model (i.e., the WIN-US-SBM model), as a comprehensive ecoefficiency assessment method, and the main influencing factors of eco-efficiency were analyzed through the Tobit regression model. Shuai and Fan [28] used the superefficient DEA model to measure the efficiency of Chinese green economy, and the Tobit model is applied to examine the impact of environmental regulation on the efficiency of Chinese regional green economy extent and direction.

\section{Methodologies}

\subsection{DEA Models}

3.1.1. Classical DEA-CCR Model and Its Development. Suppose there is a set of $N$ DMUs, each $\operatorname{DMU}_{t}(t=1, \ldots, N)$ produces $J$ different outputs $y_{j}^{t}(j=1, \ldots, J)$ utilizing $I$ different inputs $x_{i}^{t}(I=1, \ldots, I) ;\left(x^{t}, y^{t}\right)$ is a positive known input-output vector for the $\mathrm{DMU}_{t}$. There is the fractional programming model $[19,32]$ :

$$
\begin{aligned}
& \max \quad \mathrm{TE}_{t}=\frac{\sum_{j=1}^{j} u_{j} y_{j}^{t}}{\sum_{i=1}^{I} v_{i} x_{i}^{t}} \\
& \text { s.t. }\left\{\begin{array}{l}
\sum_{j=1}^{J} u_{j} y_{j}^{n}-\sum_{i=1}^{I} v_{i} x_{i}^{n} \leq 0 \\
\sum_{i=1}^{I} v_{i} x_{i}^{t}=1 \\
v_{i}, u_{j} \geq 0 ; i=1, \ldots, I ; j=1, \ldots, J ; n=1, \ldots, N .
\end{array}\right.
\end{aligned}
$$

It can be proved that the expression (2) is equivalent to the linear programming model, namely, the input-oriented DEA-CCR model (i.e., expression (3)) which assumes the existence of constant returns-to-scale (CRS). The maximum $\mathrm{TE}_{t}$ of the objective function given by the DEA-CCR model is called technical efficiency (TE) of $\mathrm{DMU}_{t}$, where $\mathrm{TE} \leq 1$ :

$$
\begin{aligned}
& \max \mathrm{TE}_{t}=\sum_{j=1}^{J} u_{j} y_{j}^{t} \\
& \text { s.t. }\left\{\begin{array}{l}
\sum_{j=1}^{J} u_{j} y_{j}^{n}-\sum_{i=1}^{I} v_{i} x_{i}^{n} \leq 0 \\
\sum_{i=1}^{I} v_{i} x_{i}^{t}=1 \\
v_{i}, u_{j} \geq 0 ; i=1, \ldots, I ; j=1, \ldots, J ; n=1, \ldots, N .
\end{array}\right.
\end{aligned}
$$

In 1984, the DEA method was improved again, and Banker et al. [33] extended the DEA-CCR model to the DEA-BCC model under the assumption of variable returnsto-scale. However, both the classical DEA-CCR model and the DEA-BCC model have their shortcomings: (1) when the number of DMU is few, the number of inputs and outputs is too many, and the cases that many DMUs are at the efficiency boundary often happens, so the relative efficiency of these effective DMUs will not be effectively distinguished. (2) The classical DEA model relies on a basic assumption that the input must be reduced as much as possible, and the output must be expanded as much as possible. However, this is often not the case with real production activities. Some production processes are accompanied by environmental pollutants (it is also called undesirable outputs), but the traditional DEA model ignores the undesirable outputs, and the slack problem of inputs and outputs cannot be fully considered at the same time, so the efficiency value of the measurement may be inaccurate or biased.

To solve problem (1), the superefficient DEA model proposed by Andersen et al. in 1993 is the most widely used method at present [34]. In order to achieve the total ordering 
of all $\mathrm{DMU}_{i}(i=1,2, \ldots, n)$, the basic idea is that the $\mathrm{DMU}_{j}$ can be removed from the efficiency boundary when evaluating the $\mathrm{DMU}_{j}$. Based on the rest of $\operatorname{DMU}_{s}(s=1,2, \ldots, n$, $s \neq j$ ), a new efficiency boundary can be built and the distance between the $\mathrm{DMU}_{j}$ and the new efficiency boundary can be calculated. The formula can be written as follows (more information can be seen in [34]):

$$
\begin{aligned}
& \min \theta_{0} \\
& \text { s.t. }\left\{\begin{array}{l}
\sum_{\substack{j=1 \\
j \neq 0}}^{n} x_{i j} \lambda_{j} \leq \theta x_{i 0}, \quad i=1,2, K, m \\
\sum_{\substack{j=1 \\
j \neq 0}}^{n} y_{r j} \lambda_{j} \geq y_{r 0}, \quad r=1,2, K, s \\
\lambda_{j} \geq 0, \quad j \neq 0 .
\end{array}\right.
\end{aligned}
$$

To solve the problem (2), Tone et al. [35] constructed a nonradial and nonoriented SBM-DEA model to solve the problem of the input and output slacks, which avoids the radial and oriented deviation. Unlike the classical DEA-CCR and DEA-BCC model, the slack variables of the SBM-DEA model are directly added to the target function, so its performance is better than the classical DEA models in reflecting the essence of efficiency measurement. To better solve the relationship between input and output variables and environmental pollution, Tone et al. [36] constructed the SBM-DEA model with undesirable outputs, and the formula can be written as follows (more information can be seen in [36]):

$$
\begin{aligned}
& \min \theta_{0}=\frac{1-(1 / m) \sum_{i=1}^{m}\left(s_{i}^{-} / x_{i 0}\right)}{1+\left(1 /\left(s_{1}+s_{2}\right)\right)\left(\sum_{r=1}^{s_{1}}\left(s_{r}^{g+} / y_{r 0}^{g}\right)+\sum_{r=1}^{s_{2}}\left(s_{r}^{b-} / y_{r 0}^{b}\right)\right)} \\
& \text { s.t. }\left\{\begin{array}{l}
\sum_{j=1}^{n} \lambda_{j} x_{i j}+s^{-}=\theta_{0} x_{i 0} \\
\sum_{j=1}^{n} \lambda_{j} y_{r j}+s^{b-}=\theta_{0} y_{r 0}^{b}, \quad r=1,2, \ldots, s_{1} \\
\sum_{j=1}^{n} \lambda_{j} y_{r j}-s^{g+}=\theta_{0} y_{r 0}^{g}, \quad r=1,2, \ldots, s_{2} \\
\lambda_{j} \geq 0, s^{-} \geq 0, s^{g+} \geq 0, s^{b-} \geq 0 .
\end{array}\right.
\end{aligned}
$$

3.1.2. A New SeUo-SBM-DEA Model. Modern industrial production is often accompanied by undesirable environmental pollution outputs such as waste water and gas, so when constructing the eco-efficiency of industrial investment, the environmental impact is taken into account. At present, the SBM-DEA model with undesirable outputs proposed in [36] is the most widely used method to assess the efficiency of DMUs with undesirable outputs [11,37-39]. On the contrary, when there are few DMUs but there are many input and output variables, the situation that many DMUs are at the reference set often happens, so the relative efficiency of these effective DMUs will not be effectively distinguished $[28,34,40]$.

Therefore, based on the framework of [36], we construct a new SeUo-SBM-DEA model by removing the $\mathrm{DMU}_{j}$ to be evaluated from the reference set; i.e., a new constraint condition $j \neq 0$ is added to the three restrictions in expression (6) and building a new reference set based on the rest of DMUs to achieve the total ranking of all DMUs, and the model expression is as follows:

$$
\begin{aligned}
& \min \theta_{0}=\frac{1-(1 / m) \sum_{i=1}^{m}\left(s_{i}^{-} / x_{i 0}\right)}{1+\left(1 /\left(s_{1}+s_{2}\right)\right)\left(\sum_{r=1}^{s_{1}}\left(s_{r}^{g+} / y_{r 0}^{g}\right)+\sum_{r=1}^{s_{2}}\left(s_{r}^{b-} / y_{r 0}^{b}\right)\right)} \\
& s . t . \quad\left\{\begin{array}{l}
\sum_{\substack{j=1 \\
j \neq 0}}^{n} \lambda_{j} x_{i j}+s^{-}=\theta_{0} x_{i 0} \\
\sum_{j=1}^{n} \lambda_{j} y_{r j}+s^{b-}=\theta_{0} y_{r 0}^{b}, \quad r=1,2, \ldots, s_{1} \\
j \neq 0 \\
\sum_{j=1}^{n} \lambda_{j} y_{r j}-s^{g+}=\theta_{0} y_{r 0}^{g}, \quad r=1,2, \ldots, s_{2} \\
j \neq 0 \\
\lambda_{j} \geq 0, s^{-} \geq 0, s^{g+} \geq 0, s^{b-} \geq 0,
\end{array}\right.
\end{aligned}
$$

where the target function value of $\theta_{0}$ is the efficiency value of $\mathrm{DMU}_{0} . x_{0}, y^{b}$, and $y^{g}$ stand for inputs, undesirable outputs, and desirable outputs of $\mathrm{DMU}_{0}$, respectively. $s^{-}$represents the slack variables of inputs, $s^{b-}$ and $s^{g+}$ represent the slack variables of desirable outputs and undesirable outputs, respectively. $m, s_{1}$, and $s_{2}$ are the number of inputs, desirable outputs, and undesirable outputs, respectively; here, we have $s_{1}+s_{2}=s$.

Model (6) is a nonlinear programming problem, it can be transformed into a linear programming problem with Charnes-Cooper transformation [41], and then, it can be solved by some DEA softwares, such PIM-DEA software, MaxDEA software, and MATLAB software.

3.2. Tobit Regression Model. The EEII value computed by a new SeUo-SBM-DEA model is in the range of 0 to 2 (as shown in Table 1), which belongs to the truncated data. Tobit regression model, also known as a censored regression model, is conducted to estimate the linear relationships between variables when there is either left or right censoring in the dependent variable. The Tobit regression model is applied because when applying the DEA methods to assess 
TABLE 1: Measurment results of EEII based on four DEA models.

\begin{tabular}{|c|c|c|c|c|c|c|c|c|c|c|c|c|}
\hline & \multicolumn{4}{|c|}{2015} & \multicolumn{4}{|c|}{2016} & \multicolumn{4}{|c|}{2017} \\
\hline & M (3) & M (4) & M (5) & M (6) & M (3) & $\mathrm{M}(4)$ & M (5) & M (6) & M (3) & M (4) & M (5) & M (6) \\
\hline Beijing & 0.955 & 0.955 & 1.000 & 1.241 & 0.911 & 0.911 & 1.000 & 1.271 & 0.942 & 0.942 & 1.000 & 1.080 \\
\hline Tianjin & 1.000 & 1.088 & 1.000 & 1.048 & 1.000 & 1.116 & 1.000 & 1.053 & 1.000 & 1.082 & 1.000 & 1.084 \\
\hline Hebei & 0.775 & 0.775 & 0.460 & 0.460 & 0.747 & 0.747 & 0.453 & 0.453 & 0.761 & 0.761 & 0.472 & 0.472 \\
\hline Shanxi & 0.443 & 0.443 & 0.236 & 0.236 & 0.370 & 0.370 & 0.199 & 0.199 & 0.376 & 0.376 & 0.199 & 0.199 \\
\hline Inner Mongolia & 0.929 & 0.929 & 0.392 & 0.392 & 0.874 & 0.874 & 0.372 & 0.372 & 0.908 & 0.908 & 0.413 & 0.413 \\
\hline Liaoning & 0.833 & 0.833 & 0.547 & 0.547 & 0.666 & 0.666 & 0.397 & 0.397 & 0.529 & 0.529 & 0.297 & 0.297 \\
\hline Jilin & 0.929 & 0.929 & 0.587 & 0.587 & 0.880 & 0.880 & 0.576 & 0.576 & 0.901 & 0.901 & 0.660 & 0.660 \\
\hline Heilongjiang & 0.599 & 0.599 & 0.319 & 0.319 & 0.537 & 0.537 & 0.282 & 0.282 & 0.522 & 0.522 & 0.267 & 0.267 \\
\hline Shanghai & 0.855 & 0.855 & 0.823 & 0.823 & 0.823 & 0.823 & 0.822 & 0.822 & 0.838 & 0.838 & 0.839 & 0.839 \\
\hline Jiangsu & 1.000 & 1.219 & 1.000 & 1.066 & 1.000 & 1.245 & 1.000 & 1.071 & 1.000 & 1.249 & 1.000 & 1.082 \\
\hline Zhejiang & 0.919 & 0.919 & 0.721 & 0.721 & 0.879 & 0.879 & 0.647 & 0.647 & 0.867 & 0.867 & 0.682 & 0.682 \\
\hline Anhui & 0.875 & 0.875 & 0.653 & 0.653 & 0.855 & 0.855 & 0.648 & 0.648 & 0.926 & 0.926 & 0.683 & 0.683 \\
\hline Fujian & 1.000 & 1.037 & 1.000 & 1.012 & 1.000 & 1.084 & 1.000 & 1.027 & 1.000 & 1.063 & 1.000 & 1.035 \\
\hline Jiangxi & 1.000 & 1.037 & 1.000 & 1.012 & 0.983 & 0.983 & 0.741 & 0.741 & 0.958 & 0.958 & 0.699 & 0.699 \\
\hline Shandong & 1.000 & 1.040 & 1.000 & 1.013 & 1.000 & 1.070 & 1.000 & 1.022 & 1.000 & 1.064 & 1.000 & 1.028 \\
\hline Henan & 0.906 & 0.906 & 0.669 & 0.669 & 0.930 & 0.930 & 0.729 & 0.729 & 0.940 & 0.940 & 0.799 & 0.799 \\
\hline Hubei & 0.798 & 0.798 & 0.578 & 0.578 & 0.808 & 0.808 & 0.600 & 0.600 & 0.860 & 0.860 & 0.649 & 0.649 \\
\hline Hunan & 0.992 & 0.992 & 0.830 & 0.830 & 0.986 & 0.986 & 0.784 & 0.784 & 1.000 & 1.005 & 1.000 & 1.002 \\
\hline Guangdong & 1.000 & 1.056 & 1.000 & 1.039 & 1.000 & 1.029 & 1.000 & 1.037 & 1.000 & 1.027 & 1.000 & 1.061 \\
\hline Guangxi & 0.972 & 0.972 & 0.634 & 0.634 & 1.000 & 1.023 & 1.000 & 1.008 & 1.000 & 1.022 & 1.000 & 1.007 \\
\hline Hainan & 0.998 & 0.998 & 0.443 & 0.443 & 0.917 & 0.917 & 0.392 & 0.392 & 0.895 & 0.895 & 0.367 & 0.367 \\
\hline Chongqing & 0.848 & 0.848 & 0.533 & 0.533 & 0.834 & 0.834 & 0.556 & 0.556 & 0.843 & 0.843 & 0.535 & 0.535 \\
\hline Sichuan & 0.686 & 0.686 & 0.454 & 0.454 & 0.718 & 0.718 & 0.482 & 0.482 & 0.737 & 0.737 & 0.474 & 0.474 \\
\hline Guizhou & 0.616 & 0.616 & 0.319 & 0.319 & 0.623 & 0.623 & 0.335 & 0.335 & 0.688 & 0.688 & 0.373 & 0.373 \\
\hline Yunnan & 0.614 & 0.614 & 0.288 & 0.288 & 0.594 & 0.594 & 0.277 & 0.277 & 0.616 & 0.616 & 0.285 & 0.285 \\
\hline Shaanxi & 0.649 & 0.649 & 0.387 & 0.387 & 0.668 & 0.668 & 0.384 & 0.384 & 0.687 & 0.687 & 0.403 & 0.403 \\
\hline Gansu & 0.703 & 0.703 & 0.327 & 0.327 & 0.633 & 0.633 & 0.288 & 0.288 & 0.603 & 0.603 & 0.278 & 0.278 \\
\hline Qinghai & 0.700 & 0.700 & 0.251 & 0.251 & 0.656 & 0.656 & 0.229 & 0.229 & 0.730 & 0.730 & 0.265 & 0.265 \\
\hline Ningxia & 0.648 & 0.648 & 0.278 & 0.278 & 0.640 & 0.640 & 0.262 & 0.262 & 0.691 & 0.691 & 0.292 & 0.292 \\
\hline Xinjiang & 0.745 & 0.745 & 0.270 & 0.270 & 0.642 & 0.642 & 0.228 & 0.228 & 0.625 & 0.625 & 0.227 & 0.227 \\
\hline Mean & 0.833 & 0.849 & 0.600 & 0.614 & 0.806 & 0.825 & 0.589 & 0.606 & 0.815 & 0.832 & 0.605 & 0.618 \\
\hline
\end{tabular}

the EEII of each province, the efficiency scores may be truncated. In such a situation where multiple samples become a certain limit value within a specific range, the general regression method cannot explain the difference in properties between the limit value and the nonlimiting observation value to ensure the consistency of the estimates [28]. Hence, when the EEII is used as a dependent variable to analyze the effect of various factors on the EEII, the estimating results of ordinary linear regression may be biased and inconsistent. To estimate the panel data, Tobit model has two types of methods: fixed effect and random effect, and both can be used. If a fixed effect model is set, the estimated value obtained using the maximum likelihood estimation method is biased and inconsistent. False and marginal effects are underestimated, so we use random effects model for maximum likelihood estimation. More researches on why the Tobit model is suitable for exploring the determinants of efficiency scores can be seen in [28-31]. Therefore, the research in this article will use the Tobit model to analyze the influencing factors of China's eco-efficiency of industrial investment and then extract the main factors affecting China's eco-efficiency of industrial investment and provide sufficient empirical data for subsequent policy recommendations. The model expression of Tobit regression is shown as follows:

$$
\left\{\begin{array}{l}
y_{i}^{*}=\beta X_{i}+\mu_{i}, \\
y_{i}=y_{i}^{*}, y_{i}^{*}>0, \\
y_{i}=0, y_{i}^{*} \leq 0,
\end{array}\right.
$$

where $y_{i}^{*}$ is the latent variable, $y_{i}$ is the dependent variable, $X_{i}$ is the independent variable vector, $\beta$ is the parameter vector, and $\mu_{i} \sim N\left(0, \sigma^{2}\right)$ is a random perturbation.

\section{Empirical Research on the Eco-Efficiency of Provincial Industrial Investment in China}

4.1. Selection of Research Samples and Input-Output Indicators. Within a productive process, inputs and outputs constitute the most essential factors. Therefore, the selection of input and output variables is imperative when measuring the eco-efficiency. The selection methods of inputs and outputs variables mainly include empirical judgment, principal component analysis, and factor analysis, and each method has its own advantages and disadvantages. According to the characteristics of industrial production activities, that is, by investing capital, labor, land, energy, and other resources, the corresponding industrial products are produced, and environmental pollutants such as waste water, waste gas, and solid waste are generated at the same 
time. To assess the eco-efficiency of industrial investment from the comprehensive perspective of economic, energy, and environmental benefits, in this paper, we choose capital, labor, and energy as three classic inputs, industrial added value as desirable output, and waste water, waste gas, and solid waste as undesirable outputs based on the preceding review of previous researches, such as in [11,42-45]. Due to the lack of available data in the Tibet Province, the research samples of this paper are 30 provinces in China: the eastern regions include 11 provinces including Beijing, Tianjin, Hebei, Liaoning, Shanghai, Jiangsu, Zhejiang, Fujian, Shandong, Guangdong, and Hainan; the central regions include 8 provinces including Shanxi, Jilin, Heilongjiang, Anhui, Jiangxi, Henan, Hubei, and Hunan; and the western regions include 11 provinces including Inner Mongolia, Guangxi, Chongqing, Sichuan, Guizhou, Yunnan, Shaanxi, Gansu, Qinghai, Ningxia, and Xinjiang.

\subsubsection{Input Indicators.}

Fixed assets investment (X1): total investment in fixed assets (unit: billion YUAN) of industrial enterprises above designated size (i.e., industrial enterprises with annual main business income of over 20 million yuan) and use the fixed asset price index to reduce it by the base period of 2001.

Total number of employees (X2): total number of employees in industrial enterprises above designated size (unit: ten thousand).

Total energy consumption (X3): total energy consumption of industrial enterprises above designated size (unit: 10,000 tons of standard coal).

4.1.2. Desirable Output. Industrial added value (Y): the final result of industrial production activities (unit: billion yuan) is expressed by industrial enterprises in the form of monetary during the reporting period and is adjusted by the exfactory price index of industrial producers in various regions based on 2001.

\subsubsection{Undesirable Outputs.}

Waste water (U1): total discharge of industrial waste water above designated size (unit: 10,000 tons).

Waste gas (U2): total discharge of industrial waste gas above designated size (unit: 10,000 tons).

Solid waste (U3): total discharge of industrial solid waste above designated size (unit: 10,000 tons).

\subsection{Descriptive Statistical Analysis of Input-Output Indicators} and Pearson Correlation Test. The datasets of input-output indicators are derived from the China Statistical Yearbook (2015-2017), China Labor Statistics Yearbook (2015-2017), and China Energy Statistics Yearbook (2015-2017). The results of descriptive statistical analysis are obtained by using SPSS software and are shown in Table 2. As can be seen from Table 2, the standard deviation of input indicators, such as fixed asset investment, total number of employees, and energy consumption of industrial enterprises, is very large, and it indicates that the distribution of input resources for industrial production in different regions is very unbalanced. Similarly, the output indicators of different regions are also very unbalanced.

According to [32], it is customary to run correlation analyses on all inputs and outputs selected for the model to see if one or more are highly correlated and then decide which may be dropped from the model. Consequently, this paper uses the input and output indicators to do the correlation analysis test. The Pearson correlation test results of the input and output indicators using SPSS software are shown in Table 3. The results show that, except for the solid waste that dose not pass the correlation test, the relationship between other output indicators and input indicators is significant positive correlation at the $5 \%$ level. Consequently, in order to meet the strong disposition of DEA method, this paper removes the solid waste when measuring the EEII value.

The number of DMUs should be at least three times the total number of inputs plus outputs used in the DEA models. This is a rule-of-thumb decision but from a practical point of view works reasonably well [46]. Often, another similar rule can offer guidance as follows: $n \geq \max \{m \times s, 3 \times(m+s)\}$, where $n=$ number of DMUs, $m=$ number of inputs, and $s=$ number of outputs [32]. In this paper, there are three inputs and three outputs, and the number of DMUs is 30 , so the number of DMUs and the total number of inputs plus outputs satisfy this rule.

4.3. Measurement Results Analysis. The measurement results computed by the model (3), model (4), model (5), and model (6) are shown in Table 1 (note: the model (3), model (4), model (5), and model (6) are abbreviated as M (1), M (2), M (3), and $M(4)$, respectively). Based on the superefficiency DEA model proposed by [34], Avkiran (2006) identified the efficient outliers with superefficiency scores equal to 2 or above [47]. As can be seen from Table 1, the DEA efficiency scores based on the SeUo-SBM-DEA model are all less than 2, so there are no efficient outliers. The model (3) does not consider the undesirable output, so the measurement results of EEII value are generally high, and there are many provinces in the frontier of efficiency at the same time, so the EEII of these provinces cannot be compared. Compared with the model (6), the model (4) can effectively rank the provinces in the frontier of efficiency, but because it does not consider the undesirable outputs, the measurement results of EEII value are higher than the actual situation. The model (5) is compared to the model (6), and they both consider undesirable outputs, so the measurement results of EEII value between them is very close; because there are many provinces in the frontier of efficiency, the model (5) cannot effectively rank those provinces.

On the one hand, the model (6) constructed in this paper considers the undesirable outputs, so the average measurement value of the EEII is at about 0.6 , which indicates that the EEII of China's industrial investment is generally low in 2015-2017. This is consistent with the actual situation that the proportion of industrial investment in China's GPD has increased year by year, while the promotion effect of 
TABLe 2: Descriptive statistical analysis of input-output indicators.

\begin{tabular}{|c|c|c|c|c|c|c|c|}
\hline & Year & Min. & Max. & Ave. & S.D. & Ske. & Kur. \\
\hline \multirow{3}{*}{$X 1$} & 2015 & 12 & 1471 & 333 & 346 & 1.935 & 3.672 \\
\hline & 2016 & 12 & 1464 & 326 & 345 & 1.959 & 3.719 \\
\hline & 2017 & 11 & 1436 & 316 & 338 & 1.973 & 3.778 \\
\hline \multirow{3}{*}{$X 2$} & 2015 & 1415 & 61985 & 18783 & 14603 & 1.810 & 3.409 \\
\hline & 2016 & 1682 & 67467 & 20090 & 15509 & 1.870 & 3.601 \\
\hline & 2017 & 1903 & 72768 & 21664 & 16897 & 1.928 & 3.752 \\
\hline \multirow{3}{*}{$X 3$} & 2015 & 1820 & 36511 & 14665 & 8536 & 0.900 & 0.259 \\
\hline & 2016 & 1938 & 37945 & 14911 & 8681 & 0.952 & 0.468 \\
\hline & 2017 & 2006 & 38723 & 15192 & 8861 & 0.963 & 0.524 \\
\hline \multirow{3}{*}{ Y } & 2015 & 1901 & 141194 & 36403 & 36819 & 1.900 & 3.210 \\
\hline & 2016 & 1833 & 147392 & 36797 & 38454 & 1.943 & 3.327 \\
\hline & 2017 & 1765 & 155820 & 38393 & 40659 & 1.931 & 3.213 \\
\hline \multirow{3}{*}{$U 1$} & 2015 & 7956 & 204890 & 68433 & 53777 & 1.138 & 0.569 \\
\hline & 2016 & 6879 & 206427 & 66483 & 53039 & 1.224 & 0.908 \\
\hline & 2017 & 27275 & 938261 & 236827 & 192999 & 1.991 & 5.181 \\
\hline \multirow{3}{*}{$U 2$} & 2015 & 31855 & 1358883 & 580072 & 340537 & 0.413 & -0.333 \\
\hline & 2016 & 22070 & 1220937 & 518857 & 300463 & 0.346 & -0.182 \\
\hline & 2017 & 17000 & 1134500 & 367443 & 246462 & 1.100 & 1.862 \\
\hline \multirow{3}{*}{$U 3$} & 2015 & 515 & 41928 & 10841 & 9559 & 1.697 & 3.019 \\
\hline & 2016 & 422 & 35372 & 10889 & 9506 & 1.407 & 1.262 \\
\hline & 2017 & 330 & 33236 & 10293 & 8548 & 1.202 & 0.867 \\
\hline
\end{tabular}

TABLE 3: Pearson correlation test of input-output indicators.

\begin{tabular}{|c|c|c|c|c|}
\hline & Year & $\mathrm{X} 1$ & $\mathrm{X} 2$ & $\mathrm{X} 3$ \\
\hline \multirow{3}{*}{ Y } & 2015 & $0.948^{* *}$ & $0.967^{* *}$ & $0.847^{* *}$ \\
\hline & 2016 & $0.950^{* *}$ & $0.965^{* *}$ & $0.835^{* *}$ \\
\hline & 2017 & $0.951^{* *}$ & $0.963^{* *}$ & $0.828^{* *}$ \\
\hline \multirow{3}{*}{$U 1$} & 2015 & $0.940^{* *}$ & $0.896^{* *}$ & $0.859^{* *}$ \\
\hline & 2016 & $0.930^{* *}$ & $0.913^{* *}$ & $0.849^{* *}$ \\
\hline & 2017 & $0.972^{* *}$ & $0.841^{* *}$ & $0.786^{* *}$ \\
\hline \multirow{3}{*}{$U 2$} & 2015 & $0.455^{*}$ & $0.627^{* *}$ & $0.819^{* *}$ \\
\hline & 2016 & $0.471^{* *}$ & $0.624^{* *}$ & $0.812^{* *}$ \\
\hline & 2017 & $0.344^{* *}$ & $0.570^{* *}$ & $0.762^{* *}$ \\
\hline \multirow{3}{*}{ U3 } & 2015 & 0.115 & 0.318 & $0.583^{* *}$ \\
\hline & 2016 & 0.078 & 0.269 & $0.539^{* *}$ \\
\hline & 2017 & 0.115 & 0.313 & $0.574^{* *}$ \\
\hline
\end{tabular}

Note. ${ }^{*}$ Significant at 0.05 (2-tailed test); ${ }^{* *}$ significant at 0.01 (2-tailed test).

industrial investment in GDP growth is not significant. On the other hand, the model (6) also has the advantage of superefficient DEA model, so it can effectively rank those DMUs in the frontier of efficiency. Therefore, the performance of model (6) is better than the models (3), (4), and (5), which is more reasonable to assess the eco-efficiency of industrial investment from the comprehensive perspective of economic, energy, and environmental benefits.

4.3.1. Overall Analysis. Figure 2 reflects the EEII in the eastern, central, and western regions and whole country from 2015 to 2017, and the following conclusions can be drawn:

(1) The average EEII in China is generally low (0.613) in 2015-2017. The main reason is that the industrial investment structure and investment growth mode are unreasonable, and China's industry still has not got rid of the industrial development mode of high- input, high-consumption, high-pollution, and lowtechnology in the past few years. Consequently, the measurement result is consistent with the actual situation that the proportion of industrial investment in China's GPD has increased year by year, while the promotion effect of industrial investment on GDP growth is not significant. The empirical result also indirectly indicates that the sustainability of China's industrial investment is generally low.

(2) The EEII in the eastern, central, and western regions exists a significant regional disparity; namely, the average value of EEII was the highest in the eastern regions (0.838), followed by the central regions (0.6) and western regions (0.397). However, the growth rate of the eco-efficiency in the western regions is significantly higher than the eastern regions and the western regions, so the disparity with them has reduced gradually. 


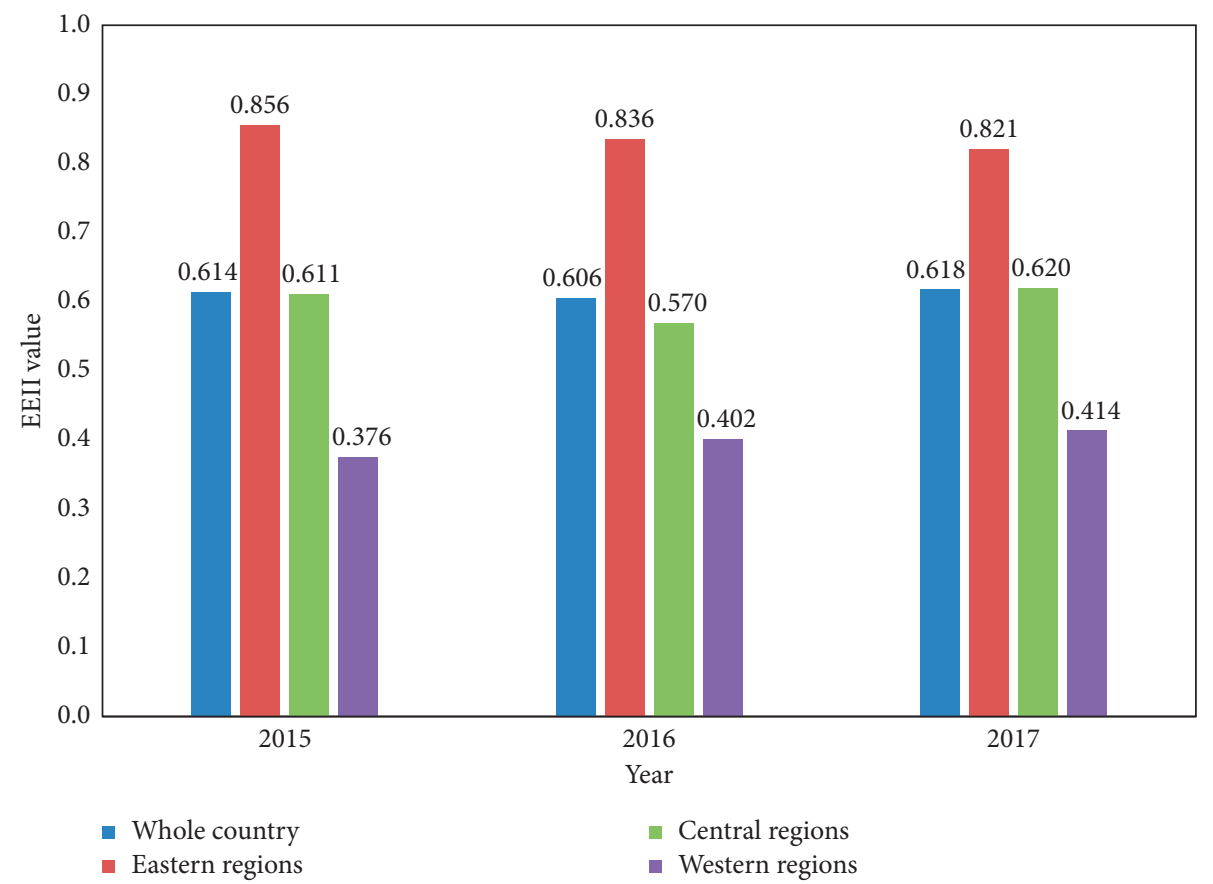

Figure 2: A comparison of the EEII in different regions in China from 2015 to 2017.

The reason for the imbalance in the EEII in the eastern, central, and western regions is that the eastern regions have taken the lead in most of the industrialization process, and it is in the later period of industrialization or the initial stage of information society. With the characteristics of high technology, high capital, and low pollution, the pollution formed in the early and middle periods of industrialization has been treated, and the economic development is characterized by sustainability. The economic development stage of the central regions is almost in the middle and late stages of industrialization, while the western regions are in the early and middle stages of industrialization. Under the traditional economic development mode, industrial production technologies are relatively backward, and energy and eco-environmental constraints have become more and more serious; the achievements of economic growth are not even enough to offset energy consumption and environment pollution. Consequently, the EEII in the eastern regions and the western regions is lower than the eastern regions.

The growth rate of the EEII in the western regions is higher than the eastern regions and the western regions from 2015 to 2017. The main reason is that the western regions are in the early and middle stages of industrialization, the scale of industrial investment is relatively small, and industrial production activities are in the stage of increasing returnsto-scale. On the contrary, since the implementation of the western development strategy from 2000, the Chinese government has increased investment and policy support for the western regions and has continuously carried out various preferential policies that are conducive to the economic development of the western regions. Consequently, the economic growth rate of the western region has been significantly higher than the whole country in recent years, and the gap between the eastern regions and the western regions has reduced gradually, which makes the EEII in the western region grow faster.

4.3.2. Provincial Analysis. Figure 3 reflects the tendency of EEII in China from 2015 to 2017, and the following conclusions can be drawn:

(1) The EEII in provinces of the eastern regions ranks the top in the whole country. In the eastern regions, the average value of EEII was the highest in Beijing, Tianjin, and Jiangsu Provinces, followed by Shanghai, Zhejiang, Fujian, Guangdong, and Shandong Provinces, while Hebei, Liaoning, and Hainan Provinces are at the lowest level.

Although Hebei Province belongs to the eastern regions, its EEII is far lower than the average level in the eastern regions. The main reason is that the industrial types of Hebei Province are mainly textile, machinery, steel, coal, petroleum, chemical, ceramics, and building materials, so Hebei Province still faces serious overproduction problems in recent years, which has caused a huge waste of resources. Hainan Province is focusing on the development of tourism, high-technology industries, and modern service industries, which pays great attention to energy conservation and environmental protection. However, at present, Hainan Province does not have the conditions to develop industries with high technology and low pollution, so the EEII of Hainan is at the lowest level.

The provinces of the eastern regions with the largest changes in EEII from 2015 to 2017 are Beijing and Liaoning Provinces. The EEII of Beijing Province in 


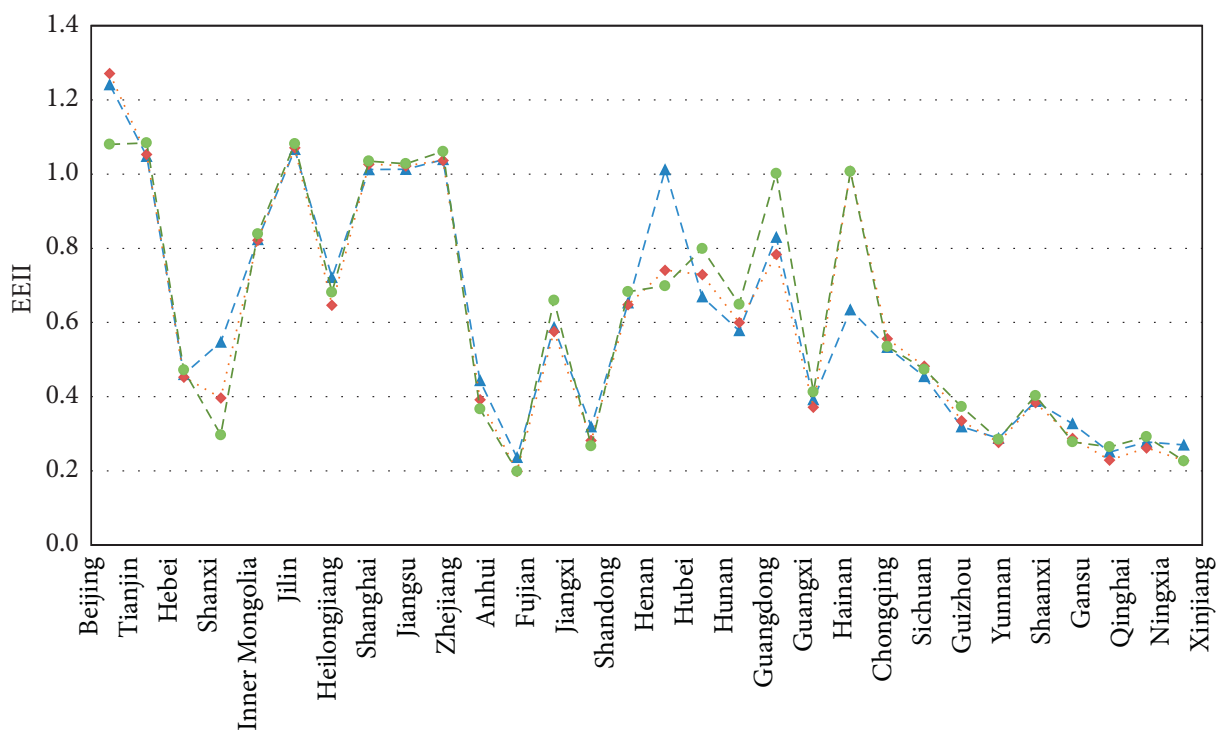

Province

$$
\begin{array}{r}
-2015 \\
-\quad 2016 \\
-\quad 2017
\end{array}
$$

FIgure 3: The tendency of the EEII in 30 provinces in China from 2015 to 2017.

2016 has decreased significantly, and the main reason is that Beijing Province has caused serious environmental problems after the industrialization, and the typical phenomenon is the appearance of haze. In order to achieve the sustainable development of economy and ecological environment, Beijing Province has begun to ban or restrict the development of the industries with low-technology and high-pollution. The EEII of Liaoning Province also has decreased year by year, the main reason is that Liaoning Province is an old industrial base, its industrial structure dominated by low value-added traditional industries has not been transformed and updated in time, and the current economic development model of high-investment, high-pollution, and low-output also has not been adjusted in time.

(2) The EEII in the central regions and the western regions is relatively low. The EEII of Hunan, Anhui, Henan, Jilin, and Jiangxi Provinces of the central regions and Guangxi Province of the western regions is a little higher than the national average level, and they are also the six provinces with the highest EEII in the central regions and the western regions. The other 13 provinces are lower than the national average level, and Shanxi, Xinjiang, Ningxia, and Qinghai Provinces are at the lowest level in the whole country. The provinces of the central regions and the western regions with the largest changes in EEII from 2015 to 2017 are Hunan, Jiangxi, and Guangxi Provinces, and the EEII of Hunan Province had increased greatly in 2017; Guangxi Province had increased greatly in 2016, while Jiangxi Province had decreased significantly in 2017.
4.4. Kruskal-Wallis Rank Test. The above is a visual comparison of the measurement result of the EEII in the eastern, central, and western regions, and the conclusion is that the EEII of different regions exists in a regional disparity, but whether this conclusion is statistically significant needs a statistical test. Statistical test method usually includes parametric and nonparametric tests. The parameter test is a method of inferring parameters such as mean or variance of the overall distribution, when the form of population distribution is known. However, in the process of data analysis, for various reasons, people often cannot make simple assumptions about the overall distribution pattern, and the method of parameter verification is no longer applicable. The nonparametric test is a method based on this consideration, which uses the sample data to infer the form of population distribution, when the population variance is unknown or little known. Since the nonparametric test method does not involve parameters related to the overall distribution in the inference process, it is called the nonparametric test.

The Kruskal-Wallis rank test is a widely used nonparametric test method, it compares the rank of two or more samples, and it is essentially a generalization of the Wilcoxon rank sum test method for two samples. The basic principle of Kruskal-Wallis rank test is to use the sum of the squares of the groups divided by the total sample rank variance to construct the Kruskal-Wallis $\mathrm{H}$ test statistic as a powerful basis for determining whether there is a difference between the groups. More information and application about the Kruskal-Wallis rank test can be seen in [48-51]. Since the overall distribution of the EEII in the eastern, central, and western regions is unknown, the Kruskal-Wallis rank test is used for the statistical test. We use the SPSS 20.0 software to 
do the Kruskal-Wallis rank test, and the results are shown in Table 4.

As can be seen from Table 4, the Kruskal-Wallis $\mathrm{H}$ test statistic of the EEII in the eastern, central, and western regions in 2015, 2016, and 2017 is 14.117, 11.669, and 9.331, respectively, and they are all smaller than the chi-square threshold of $\mathrm{d} f=2$, so the null hypothesis should be rejected. We can also draw the same conclusion from the $p$ value, and the $p$ value for 2015,2016 , and 2017 is less than 0.05 , namely, rejecting the null hypothesis. Therefore, the conclusion that the EEII in the eastern, central, and western regions exists in a significant regional disparity passes the Kruskal-Wallis rank test and has statistical significance, which is consistent with the visual analysis of above.

The box diagram of Kruskal-Wallis rank test is shown in Figure 4, and we can draw the following conclusions: (1) the median value of the EEII in the eastern, central, and western regions in 2015, 2016, and 2017 is significantly different, and the median value of the eastern regions is significantly higher than the central and western regions, and the central regions are significantly higher than the western regions, which indicate that the EEII in the eastern, central, and western regions has typical nonequilibrium characteristics again. (2) The western regions have the lowest median value and the range of fluctuation, which indicates that the EEII of the western region is relatively low, but the gap of provinces in the western regions is relatively small, so the EEII of each province in the western regions is relatively balanced. (3) The eastern regions have the highest median value and the range of fluctuation, which indicates that the EEII of the eastern regions is relatively high, but the gap of provinces in the eastern regions is relatively big, so the EEII of each province in the eastern regions has a typical nonequilibrium characteristic, and this nonequilibrium characteristic has a tendency to expand gradually.

\section{Influencing Factors Analysis of the Eco- Efficiency of Industrial Investment}

5.1. Regression Variables Selection and Data Sources. In this paper, the dependent variable is the eco-efficiency calculated by a new superefficient SBM-DEA model with undesirable output. Research and development expenditure (unit: 100 million yuan), investment in treatment of industrial pollution sources (unit: 100 million yuan), gross domestic product (unit: 100 million yuan, and we employ the logarithmic form of GDP to smooth data when solving the model), foreign direct investment (converting to CNY based on the average exchange rate of RMB to USD, unit: 100 million yuan), total education funds (unit: 100 million yuan), and total import and export trade (converting to CNY based on the average exchange rate of RMB to USD, unit: 100 million yuan) are selected to investigate the effect of these factors on the eco-efficiency of industrial investment, and the datasets of factors are derived from the China Statistical Yearbook (2017) and China Education Statistic Yearbook (2017):
(1) Research and development expenditure (RD): RD of industrial enterprises above designated size includes direct expenditures for $\mathrm{R} \& \mathrm{D}$ projects, management and service fees for R\&D activities, capital construction expenditure, and outsourcing processing fee. $\mathrm{RD}$ is an effective way to reduce production costs and improve quality of products, so as to increase the competitiveness of industrial enterprises [52]. Usually, the more $\mathrm{RD}$ a country invests, the more competitive the science and technology, which can increase productivity and reduce resource consumption and environmental pollution. Luan et al. [53] used both linear and nonlinear analyses to analyze the effect of domestic RD on China's industrial carbon intensity, and the estimation results show that domestic RD from domestic and abroad is conducive to reducing carbon intensity.

(2) Investment in treatment of industrial pollution (IP) sources: with the rapid development of China's economy and the continuous acceleration of the industrialization process, the environmental pollution phenomenon caused by the increasing emissions of industrial "three wastes" is becoming increasingly serious. Because the awareness of environmental protection of the Chinese government and industrial enterprises has gradually increased, the IP in China is increasing year by year. Obviously, the IP contributes to environmental protection, and then, it may affect the eco-efficiency of industrial investment.

(3) Gross domestic product (GDP): GDP is the total value of all the final goods and services produced within a country's borders in a specific period. Usually, GDP can reflect the economic development level of the society; meanwhile, economic growth has always been closely connected with eco-efficiency [11], so GDP is often used as an indicator for measuring the economic situation of a country (for more details, please see $[54,55])$.

(4) Foreign direct investment (FDI): FDI is a special form of capital flow, which includes intangible assets such as capital and management skills [56]. The determinants of FDI flows include differences in the marginal rate of return on capital, the size of the host country's market, exchange rate risk, trade barriers, and market power [57]. Since the reform and opening up in 1978, the Chinese economy has experienced rapid growth for more than 40 years, and the FDI has also expanded year by year. FDI has an important impact on the productivity, exporting activity, and innovation of Chinese domestic firms, as well as on the nation's labor markets [58], so it may affect the performance of industrial investment.

(5) Total education funds (EF): EF includes national finance, social donations, and other sources of education funds. Usually, the more TEF a country 
TABLE 4: The results of Kruskal-Wallis rank test.

\begin{tabular}{lccc}
\hline & 2015 & 2016 & 2017 \\
\hline Kruskal-Wallis H test statistic & 14.117 & 11.669 & 9.331 \\
$p$ value & 0.001 & 0.003 & 0.009 \\
\hline
\end{tabular}

Note. (1) The total observation sample is 30 , and the number of observation samples in the eastern, central, and western regions is 11,8 , and 11 , respectively. (2) The degree of freedom is $\mathrm{d} f=3-1=2$, and the corresponding chi-square threshold is 5.991. (3) The significance level is 0.05 (2-tailed test), and the test statistic is adjusted for ties.

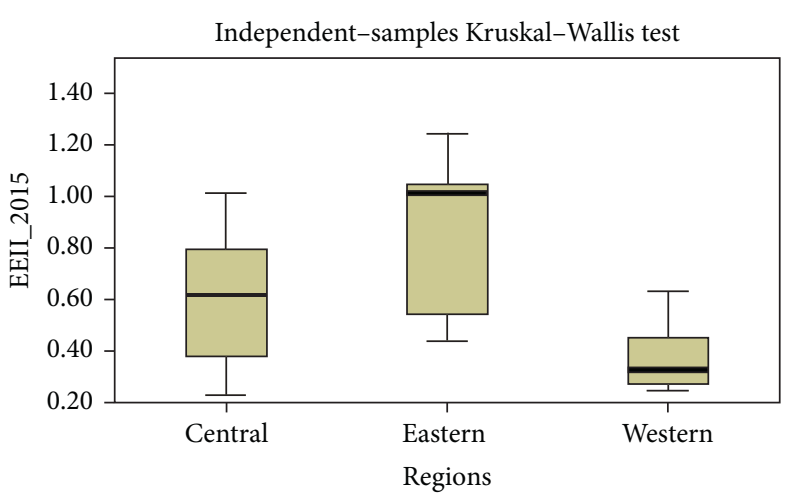

(a)

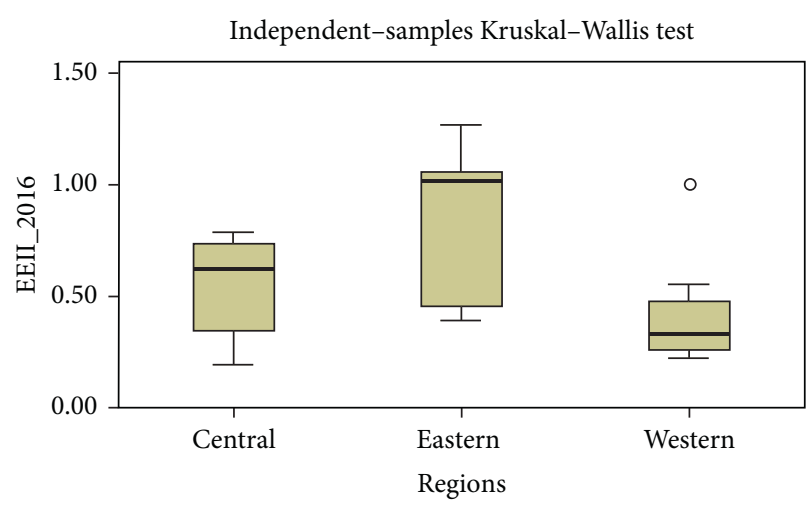

(b)

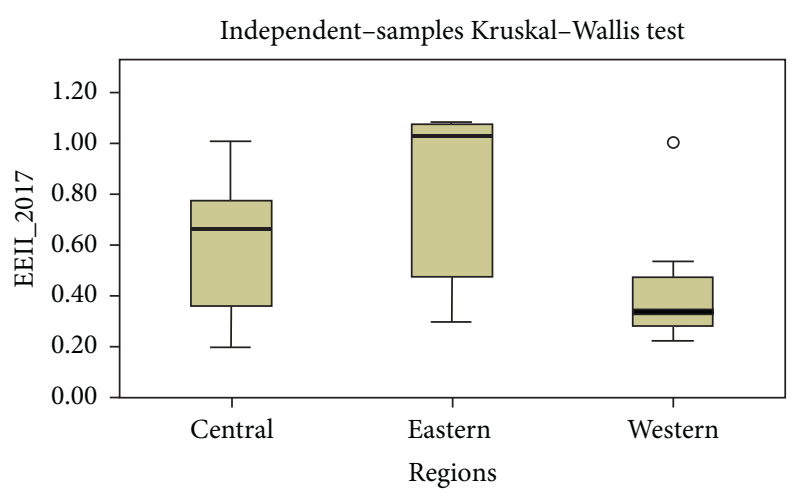

(c)

Figure 4: The box diagram of Kruskal-Wallis rank test in (a) 2015, (b) 2016, and (c) 2017.

invests, the higher the quality of laborers, so as to promote the transformation of scientific and technological achievements. TEF is the material basis for developing intelligence and educational undertakings, which is also an important factor affecting economic and social development.

(6) Total import and export trade (IET): IET provides a measure of the level of China's foreign trade, which can regulate the utilization rate of domestic production factors, improve the international supply and demand relationship, and adjust the economic structure. Liu et al. [11] evaluated the eco-efficiency of 285 Chinese cities based on an "undesirable output SBM-DEA models" and found that import and export trade had significant positive influence on the eco-efficiency of 285 Chinese cities.

According to model (7) and above factors, the following multiple linear regression models can be established:

$$
\begin{aligned}
\mathrm{EEII}= & \beta_{0}+\beta_{1} \mathrm{RD}_{i}+\beta_{2} \mathrm{IP}_{i}+\beta_{3} \ln \mathrm{GDP}_{i} \\
& +\beta_{4} \mathrm{FDI}_{i}+\beta_{5} \mathrm{EF}_{i}+\beta_{6} \mathrm{IET}_{i}+\varepsilon_{i},
\end{aligned}
$$

where $\beta_{0}$ is the intercept term, $\beta_{1}, \beta_{2}, \ldots, \beta_{6}$ is the regression coefficient of independent variables, $\varepsilon_{i}$ is the residual term of the regression model, and $i(i=1,2, \ldots, 30)$ is the observation.

5.2. Regression Results Analysis. We examine the effect of factors on the eco-efficiency of industrial investment using Eviews 10 software, and the regression results shown in Table 5 show that, in addition to IET, the other five factors pass the significance test.

As can be seen from Table 5, the following conclusions can be drawn.

$\mathrm{R} \& \mathrm{D}$ expenditure is positively correlated with the ecoefficiency of industrial investment and significant at the 0.1 confidence level, with a 1-unit increase in $\mathrm{R} \& \mathrm{D}$ expenditure 
TABLE 5: Results of Tobit regression model.

\begin{tabular}{lcccc}
\hline & Coefficient & Standard error & $T$-statistic & Prob. \\
\hline$\beta_{0}$ & -1.253 & 0.875 & -1.433 & 0.152 \\
RD & $0.001^{*}$ & 0.000 & 1.668 & 0.095 \\
IP & $-0.005^{* *}$ & 0.002 & -1.949 & 0.051 \\
LNGDP & $0.202^{* *}$ & 0.102 & 1.975 & 0.048 \\
FDI & $0.018^{* *}$ & 0.007 & 2.510 & 0.012 \\
EF & $-0.002^{* *}$ & 0.001 & -1.984 & 0.047 \\
IET & -0.000 & 0.000 & -0.665 & 0.506 \\
\hline
\end{tabular}

Note. ${ }^{* *}$ Significant at $0.05 ;{ }^{*}$ significant at 0.1 .

being accompanied by a 0.001 -unit increase in eco-efficiency of industrial investment. R\&D expenditure is an important indicator reflecting a country's scientific and technological strength, and it is also an important basis for improving the country's overall strength and competitiveness. The results of many previous empirical researches show that local R\&D activities and $\mathrm{R} \& \mathrm{D}$ activities in neighboring (or foreign) regions had a significant positive impact on local technological innovation capabilities and even economic growth, such as $[59,60]$. R\&D expenditure also benefits environmental sustainability, and Adedoyin et al. [61] examined the role of R\&D expenditure on environmental sustainability in European Union-28 countries and found that the $R \& D$ expenditure had a positive impact on attaining Sustainable Development Goals. Therefore, the conclusion that R\&D expenditure had a significant positive effect on the eco-efficiency of industrial investment is reasonable.

Gross domestic product had a significant positive effect on the eco-efficiency of industrial investment, passing the 5\% significant level test. For every 1\% enhancement in gross domestic product, the corresponding increase in eco-efficiency was 0.202 . Gross domestic product refers to the total monetary or market value of the production activities of all resident units of a country or region in a certain period, which is often recognized as an important indicator to measure the economic development level of a country or region. In general, the growth of gross domestic product improves the economic development level of a country or region, while the higher requirements associated with improvements in economic structure and social structure can in turn strengthen technological innovation and industrial upgrading, thus promoting improvements in eco-efficiency of industrial investment. Liu et al. [11] had also drawn a similar conclusion; namely, gross domestic product can promote improvements in eco-efficiency of 258 Chinese cities.

Foreign direct investment is shown to impart a positive effect with respect to the eco-efficiency of industrial investment and pass the 5\% significant level test. A 1-unit increase in foreign direct investment leads to a 0.018-unit increase eco-efficiency of industrial investment. Foreign direct investment is not only a transnational flow of capital, but also an international exchange of technology and management mode. By providing capital, technology, and management skills to host countries, foreign direct investment can promote the productivity and economic development level of host countries [62]. Meanwhile, foreign direct investment can also increase the export capacity of the host country and increase local employment [63]. In addition, by increasing the added value of products, promoting technological innovation, and technology spillover, foreign direct investment also helps to optimize the allocation of resources in the host country, improve resource utilization, and thereby promote regional economic development [64]. Therefore, a series of positive effects of foreign direct investment have promoted the eco-efficiency of industrial investment.

Investment in treatment of industrial pollution sources is negatively correlated with the eco-efficiency, and a 1-unit increase in investment in treatment of industrial pollution sources is being accompanied by a 0.005 -unit decrease in eco-efficiency of industrial investment. We will explain this result in the following two aspects: (1) according to the Environmental Kuznets Curve (EKC), we know the relationship between environmental pollution and economic growth is an inverted $U$-shaped curve [65]. However, China is still in extensive pattern of economic growth, and China's industry has not yet got rid of the industrial development mode of low-technology and high-pollution in the past few years, so China's energy consumption and industrial pollutant emissions increase sharply with the rapid economic growth in the left part of the EKC. (2) At present, the investment structure of treatment of industrial pollution sources is unreasonable and the investment efficiency was relatively low, which limited the effect of invested investment [66], so industrial pollution emissions have not been effectively controlled. For example, severe haze phenomenon has appeared in more and more cities in China. For the above two reasons, the economic losses of environmental pollution in China are not even enough to offset the capital investment of environmental protection, thereby reducing the improvement of the eco-efficiency.

The results also indicate that the total education funds are negative and significant at the 0.05 confidence level. A 1unit increase in total education funds leads to a 0.002 -unit decrease eco-efficiency of industrial investment. In endogenous growth theory, education expenditure is an investment in human capital, and human capital is regarded as an important determinant of sustainable socioeconomic development, thereby promoting economic growth $[67,68]$. In explaining our result, we argue that the total education funds only had a negative impact on the eco-efficiency in the short term, and it plays a positive role in the long run; this result is consistent with the finding of [69]. In general, education investment has a lag influence on its outputs such as economic and environmental benefits [70], which also can explain our result.

Other influencing factors such as total import and export trade are negatively correlated with the eco-efficiency, but it has no significant impact. On the whole, the positive effect of gross domestic product (namely, economic development level) and foreign direct investment on the eco-efficiency of industrial investment is far greater than the negative impact of investment in treatment of industrial pollution sources and total education funds, while the impact of R\&D expenditure on the eco-efficiency is very limited. 


\section{Conclusions and Policy Implications}

This paper constructs the eco-efficiency of industrial investment by taking energy consumption (i.e., resources input), economic benefits (i.e., desirable economic benefit output), and environmental impact (i.e., undesirable environmental pollution outputs) into account. Meanwhile, a new superefficient undesirable-output slack-based measure DEA (SeUo-SBM-DEA) model is proposed and employed to assess the eco-efficiency of industrial investment of 30 provinces in China from 2015 to 2017 . The SeUo-SBM-DEA model not only considers the undesirable outputs (such as industrial pollutant emissions) in industrial production activities but also can achieve the total ranking of all DMUs by removing the $\mathrm{DMU}_{j}$ to be evaluated from the efficiency boundary and building a new efficiency boundary based on the rest of DMUs. The empirical results show that the ecoefficiency of China's industrial investment is generally low (0.613) and exists in a significant regional disparity at the same time; namely, the average value of EEII was the highest in the eastern regions (0.838), followed by the central regions (0.6) and western regions (0.397). However, the growth rate of the eco-efficiency in the western regions is significantly higher than the eastern and central regions, so the disparity with them has reduced gradually. In addition, the eco-efficiency disparity between provinces in the western region is relatively small, while in the eastern regions, the eco-efficiency disparity of different provinces is polarized, and this imbalance has a tendency to expand gradually.

The results of the Tobit regression indicate that $R \& D$ expenditure, economic development level, and foreign direct investment all had a significant positive effect on the ecoefficiency of industrial investment, while investment in treatment of industrial pollution sources and total education funds all had a significant negative effect. Therefore, the main policy implications from this study are discussed as follow. Firstly, the government should increase R\&D expenditure in green industries, attracting more high-quality foreign direct investment to green industries, thereby promoting industrial technology upgrades and technological innovation. Meanwhile, the government should adjust the structure of environmental governance investment based on the actual situation in each region, optimizing the level of environmental governance capital allocation, so as to improve the performance of environmental governance investment. In addition, while pursuing GDP growth, we should pay more attention to the quality of economic development and achieve sustainable development in the process of developing a green economy. For instance, the government should unswervingly implement strict environmental access standards in the development of industrial enterprises, constructing a series of sustainable development standards and the evaluation system to measure the sustainability of industrial enterprises, and the sustainability of industrial enterprises should be considered when assessing the credit rating. In this way, industrial enterprises can rerecognize the importance of green production and make more efforts to enhance the capacity of green development. Finally, Chian's industrial investment should implement the green investment strategy to promote green growth; namely, the sustainable development of the invested industry should be fully considered when making investment decisions. Specifically, industrial investment should pay more attention to industries with high level of sustainability, and the proportion of industrial investment in green industry should increase to promote the development of green industries with high technology, low consumption, and low pollution. Meanwhile, the government should emphasize the quality of infrastructure investment and construction so as to enhance the capacity of infrastructure to support the eco-efficiency.

A number of new insights about eco-efficiency of industrial investment are based on the SeUo-SBM-DEA model, which have practical significance for policy-making. Future extensions will be studied from the following aspects. The Tibet Province is not included in the study area because of the lack of available data, which may affect the results of the study, so the further study should address this gap. On the other hand, further researches can consider and apply some of the latest tests or techniques to overcome the classic DEA downsides to provide unbiased estimates (such as $[71,72])$. Finally, the SeUo-SBM-DEA model does not consider the lag influence of industrial investment and the internal process of industrial production. Therefore, further research can attempt to construct a multiperiod network DEA model for measuring the eco-efficiency of industrial investment.

\section{Data Availability}

The data used in this paper will be available on request to the corresponding author.

\section{Conflicts of Interest}

The authors declare that there are no conflicts of interest.

\section{Acknowledgments}

The authors wish to thank Ferrara Massimiliano and Jerlie Laguras for their insightful and constructive comments and suggestions, as results in the paper have been improved substantially. Meanwhile, this paper has been funded by the Fundamental Research Funds for the Central Universities (Grant nos. 331510004007000002 and JBK2107182).

\section{References}

[1] CAICT (China Academy of Information and Communication Technology), China Industrial Development Research Report (2019), CAICT, Beijing, China, 2019, http://www.caict.ac.cn/ $\mathrm{kxyj} / \mathrm{qwfb} / \mathrm{bps} / 201911 / \mathrm{t} 20191113 \_269402 . \mathrm{htm}$.

[2] Y. Yu, J. Huang, and N. Zhang, "Industrial eco-efficiency, regional disparity, and spatial convergence of China's regions," Journal of Cleaner Production, vol. 204, pp. 872-887, 2018.

[3] Z. Chang, P. Mao, and J. Zhang, "Is there a structural bonus phenomenon in China's industrial investment since the reform and opening-up? An empirical analysis based on shiftshare method analysis," Modern Economic Science, vol. 41, no. 1, pp. 112-122, 2019, in Chinese. 
[4] M. Ferrara, M. Gangemi, L. Guerrini, and B. A. Pansera, "Distributed time delay energy model for sustainable Economic growth," Archistor, vol. 6, pp. 652-659, 2019.

[5] M. Ferrara, M. Gangemi, L. Guerrini, and B. A. Pansera, "Stability and Hopf bifurcation analysis of a distributed time delay energy model for sustainable economic growth," Atti della Accademia Peloritana dei Pericolanti, Classe di Scienze Fisiche Matematiche e Naturali, vol. 98, no. 1, 2020.

[6] J. Zhang, Y. Liu, Y. Chang, and L. Zhang, "Industrial ecoefficiency in China: a provincial quantification using threestage data envelopment analysis," Journal of Cleaner Production, vol. 143, pp. 238-249, 2017.

[7] MIIT (Ministry of Industry and Information Technology of China), Industrial Green Development Plan (2016-2020), MIIT, Beijing, China, 2016, http://www.miit.gov.cn/ n1146295/n1652858/n1652930/n3757016/c5143553/content. html.

[8] Y. Qiu, Y. D. Wang, and J. Wang, "Implied discount rate and payback threshold of energy efficiency investment in the industrial sector," Applied Economics, vol. 47, no. 21, pp. 2218-2233, 2015.

[9] A. Trianni, E. Cagno, F. Marchesani, and G. Spallina, "Classification of drivers for industrial energy efficiency and their effect on the barriers affecting the investment decisionmaking process," Energy Efficiency, vol. 10, no. 1, pp. 199-215, 2016.

[10] S. Schaltegger and A. Sturm, "Ökologische rationalität," Die Unternehmung, vol. 44, no. 4, pp. 273-290, 1990.

[11] Q. Liu, S. Wang, B. Li, and W. Zhang, "Dynamics, differences, influencing factors of eco-efficiency in China: a spatiotemporal perspective analysis," Journal of Environmental Management, vol. 264, Article ID 110442, 2020.

[12] T. Kuosmanen, "Measurement and analysis of eco-efficiency: an economist's perspective," Journal of Industrial Ecology, vol. 9, no. 4, pp. 15-18, 2005.

[13] B. Zhang, J. Bi, Z. Fan, Z. Yuan, and J. Ge, "Eco-efficiency analysis of industrial system in China: a data envelopment analysis approach," Ecological Economics, vol. 68, no. 1-2, pp. 306-316, 2008.

[14] J. Huang, X. Yang, G. Cheng, and S. Wang, “A comprehensive eco-efficiency model and dynamics of regional eco-efficiency in China," Journal of Cleaner Production, vol. 67, pp. 228-238, 2014.

[15] Y. Fan, B. Bai, Q. Qiao, P. Kang, Y. Zhang, and J. Guo, "Study on eco-efficiency of industrial parks in China based on data envelopment analysis," Journal of Environmental Management, vol. 192, pp. 107-115, 2017.

[16] A. Emrouznejad and G. Yang, "A survey and analysis of the first 40 years of scholarly literature in DEA: 1978-2016," Journal of Socio-Economic Planning Sciences, vol. 61, no. 1, pp. 1-5, 2018.

[17] H. Lydall, "Neoclassical theory," in A Critique of Orthodox EconomicsPalgrave Macmillan, London, UK, 1998.

[18] M. J. Farrell, "The measurement of productive efficiency," Journal of the Royal Statistical Society. Series A (General), vol. 120, no. 3, pp. 253-281, 1957.

[19] A. Charnes, W. W. Cooper, and E. Rhodes, "Measuring the efficiency of decision making units," European Journal of Operational Research, vol. 2, no. 6, pp. 429-444, 1978.

[20] S. C. Ray and A. Das, "Distribution of cost and profit efficiency: evidence from Indian banking," European Journal of Operational Research, vol. 201, no. 1, pp. 297-307, 2010.

[21] S. Xiao, "Environmental efficiency evaluation of Chinese industry systems by using non-cooperative two-stage DEA model," Mathematical Problems in Engineering, vol. 2019, Article ID 9208367, 10 pages, 2019.

[22] L. Zhao, Y. Zha, and L. Liang, "Uncertainty, risk, and the efficiencies of the principal and the agent: a chance constrained data envelopment analysis approach," Mathematical Problems in Engineering, vol. 2018, Article ID 8373614, 13 pages, 2018.

[23] F. Revelli and P. Tovmo, "Revealed yardstick competition: local government efficiency patterns in Norway," Journal of Urban Economics, vol. 62, no. 1, pp. 121-134, 2007.

[24] N. Rogge and S. De Jaeger, "Evaluating the efficiency of municipalities in collecting and processing municipal solid waste: a shared input DEA-model," Waste Management, vol. 32, no. 10, pp. 1968-1978, 2012.

[25] A. M. Pereira and J. M. Andraz, "On the economic and fiscal effects of investments in road infrastructures in Portugal," International Economic Journal, vol. 25, no. 3, pp. 465-492, 2010.

[26] M. Goto, A. Otsuka, and T. Sueyoshi, "DEA (data envelopment analysis) assessment of operational and environmental efficiencies on Japanese regional industries," Energy, vol. 66, no. 4, pp. 535-549, 2014.

[27] S. K. Mandal and S. Madheswaran, "Environmental efficiency of the Indian cement industry: an interstate analysis," Energy Policy, vol. 38, no. 2, pp. 1108-1118, 2010.

[28] S. Shuai and Z. Fan, "Modeling the role of environmental regulations in regional green economy efficiency of China: empirical evidence from super efficiency DEA-Tobit model," Journal of Environmental Management, vol. 261, Article ID 110227, 2020.

[29] J. Liu, J. Zhang, and Z. Fu, "Tourism eco-efficiency of Chinese coastal cities-analysis based on the DEA-Tobit model," Ocean \& Coastal Management, vol. 148, pp. 164-170, 2017.

[30] Y. Wu, Y. Ke, C. Xu, X. Xiao, and Y. Hu, "Eco-efficiency measurement of coal-fired power plants in China using super efficiency data envelopment analysis," Sustainable Cities and Society, vol. 36, pp. 157-168, 2018.

[31] W. Zhu, L. Xu, L. Tang, and X. Xiang, "Eco-efficiency of the western Taiwan straits economic zone: an evaluation based on a novel eco-efficiency model and empirical analysis of influencing factors," Journal of Cleaner Production, vol. 234, pp. 638-652, 2019.

[32] W. W. Cooper, L. M. Seiford, and J. Zhu, Handbook on Data Envelopment Analysis, Springer, Boston, MA, USA, 2nd edition, 2011.

[33] R. D. Banker, A. Charnes, and W. W. Cooper, "Some models for estimating technical and scale inefficiencies in data envelopment analysis," Management Science, vol. 30, no. 9, pp. 1078-1092, 1984.

[34] P. Andersen and N. C. Petersen, "A procedure for ranking efficient units in data envelopment analysis," Management Science, vol. 39, no. 10, pp. 1261-1264, 1993.

[35] K. Tone, "A slacks-based measure of efficiency in data envelopment analysis," European Journal of Operational Research, vol. 130, no. 3, pp. 498-509, 2001.

[36] K. Tone, "Dealing with undesirable outputs in DEA: a slacksbased measure (SBM) approach," GRIPS Research Report Series, National Graduate Institute for Policy Studies, Tokyo, Japan, 2004.

[37] W. B. Liu, W. Meng, X. X. Li, and D. Q. Zhang, "DEA models with undesirable inputs and outputs," Annals of Operations Research, vol. 173, no. 1, pp. 177-194, 2010. 
[38] H. Scheel, "Undesirable outputs in efficiency valuations," European Journal of Operational Research, vol. 132, no. 2, pp. 400-410, 2001.

[39] J. Wang, S. Wang, S. Li, Q. Cai, and S. Gao, "Evaluating the energy-environment efficiency and its determinants in Guangdong using a slack-based measure with environmental undesirable outputs and panel data model," Science of the Total Environment, vol. 663, pp. 878-888, 2019.

[40] S. Suzuki and P. Nijkamp, "Winners in the urban champions league-a performance assessment of Japanese cities by means of dynamic and super-efficient DEA," Journal of Urban Management, vol. 7, no. 1, pp. 6-20, 2018.

[41] A. Charnes and W. W. Cooper, "Programming with linear fractional functionals," Naval Research Logistics Quarterly, vol. 9, no. 3-4, pp. 181-186, 1962.

[42] J. Huang, J. Xia, Y. Yu, and N. Zhang, "Composite eco-efficiency indicators for China based on data envelopment analysis," Ecological Indicators, vol. 85, pp. 674-697, 2018.

[43] X. Lin, X. Zhu, Y. Han, Z. Geng, and L. Lin, "Economy and carbon dioxide emissions effects of energy structures in the world: evidence based on SBM-DEA model," Science of The Total Environment, vol. 729, Article ID 138947, 2020.

[44] K. Rashidi and R. Farzipoor Saen, "Measuring eco-efficiency based on green indicators and potentials in energy saving and undesirable output abatement," Energy Economics, vol. 50, pp. 18-26, 2015.

[45] Y. Yu, D. Chen, B. Zhu, and S. Hu, "Eco-efficiency trends in China, 1978-2010: decoupling environmental pressure from economic growth," Ecological Indicators, vol. 24, pp. 177-184, 2013.

[46] W. W. Cooper, L. M. Seiford, and K. Tone, Data Envelopment Analysis: A Comprehensive Text with Models, Applications, References and DEA-Solver Software, Springer Science \& Business Media, New York, NY, USA, 2nd edition, 2007.

[47] N. K. Avkiran, Productivity Analysis in the Services Sector with Data Envelopment Analysis, University of Queensland Business School, The University of Queensland, Brisbane, Australia, 3rd edition, 2006.

[48] M. Kendall and A. Stuart, The Advanced Theory of Statistics, Charles Griffin and Co. Ltd, London, UK, 1979.

[49] W. H. Kruskal and W. A. Wallis, "Use of ranks in one-criterion variance analysis," Journal of the American Statistical Association, vol. 47, no. 260, pp. 583-621, 1952.

[50] S. Seigel, Nonparametric Statistics for the Behavioral Sciences, McGraw-Hill, New York, NY, USA, 1956.

[51] T. Sueyoshi and S. Aoki, "A use of a nonparametric statistic for DEA frontier shift: the Kruskal and Wallis rank test," Omega, vol. 29, no. 1, pp. 1-18, 2001.

[52] B. A. Pansera, L. Guerrini, M. Ferrara, and T. Ciano, "Bifurcation analysis of a duopoly game with R\&D spillover, price competition and time delays," Symmetry, vol. 12, no. 2, p. 257, 2020.

[53] B. Luan, J. Huang, and H. Zou, "Domestic R\&D, technology acquisition, technology assimilation and China's industrial carbon intensity: evidence from a dynamic panel threshold model," Science of the Total Environment, vol. 693, Article ID 133436, 2019.

[54] F. O. Hocaoglu and F. Karanfil, "Examining the link between carbon dioxide emissions and the share of industry in GDP: modeling and testing for the G-7 countries," Energy Policy, vol. 39, no. 6, pp. 3612-3620, 2011.

[55] P. Xie, S. Gao, and F. Sun, "An analysis of the decoupling relationship between $\mathrm{CO}_{2}$ emission in power industry and
GDP in China based on LMDI method," Journal of Cleaner Production, vol. 211, pp. 598-606, 2019.

[56] Y. Xing and C. D. Kolstad, "Do lax environmental regulations attract foreign investment?" Environmental and Resource Economics, vol. 21, no. 1, pp. 1-22, 2002.

[57] S. R. Yeaple, "The role of skill endowments in the structure of U.S. outward foreign direct investment," Review of Economics and Statistics, vol. 85, no. 3, pp. 726-734, 2003.

[58] H. Galina and L. Cheryl, Foreign Direct Investment in China: Winners and Losers, World Scientific, Singapore, 2012.

[59] D. T. Coe and E. Helpman, "International R\&D spillovers," European Economic Review, vol. 39, no. 5, pp. 859-887, 1995.

[60] J. Eaton and S. Kortum, "Engines of growth: domestic and foreign sources of innovation," Japan and the World Economy, vol. 9, no. 2, pp. 235-259, 1997.

[61] F. F. Adedoyin, A. A. Alola, and F. V. Bekun, “An assessment of environmental sustainability corridor: the role of economic expansion and research and development in EU countries," Science of the Total Environment, vol. 713, Article ID 136726, 2020.

[62] P. Pegkas, "The impact of FDI on economic growth in eurozone countries," The Journal of Economic Asymmetries, vol. 12, no. 2, pp. 124-132, 2015.

[63] B. Lin and I. N. Benjamin, "Causal relationships between energy consumption, foreign direct investment and economic growth for MINT: evidence from panel dynamic ordinary least square models," Journal of Cleaner Production, vol. 197, pp. 708-720, 2018.

[64] M. A. Nasir, T. L. Duc Huynh, and H. T. Xuan Tram, "Role of financial development, economic growth \& foreign direct investment in driving climate change: a case of emerging ASEAN," Journal of Environmental Management, vol. 242, pp. 131-141, 2019.

[65] G. M. Grossman and A. B. Krueger, "Economic growth and the environment," The Quarterly Journal of Economics, vol. 110, no. 2, pp. 353-377, 1995.

[66] Q. Feng and T. Sun, "Comprehensive evaluation of benefits from environmental investment: take China as an example," Environmental Science and Pollution Research, vol. 27, no. 13, pp. 15292-15304, 2020.

[67] N. Benos and S. Zotou, "Education and economic growth: a meta-regression analysis," World Development, vol. 64, pp. 669-689, 2014.

[68] D. W. Jorgenson and B. M. Fraumeni, "Investment in education and U.S. economic growth," The Scandinavian Journal of Economics, vol. 9, pp. 51-70, 1992.

[69] K. Sylwester, "Income inequality, education expenditures, and growth," Journal of Development Economics, vol. 63, no. 2, pp. 379-398, 2000.

[70] L. Liao, M. Du, B. Wang, and Y. Yu, "The impact of educational investment on sustainable economic growth in Guangdong, China: a cointegration and causality analysis," Sustainability, vol. 11, no. 3, p. 766, 2019.

[71] M. Finocchiaro Castro and C. Guccio, "Searching for the source of technical inefficiency in Italian judicial districts: an empirical investigation," European Journal of Law and Economics, vol. 38, no. 3, pp. 369-391, 2014.

[72] R. Ippoliti and G. Tria, "Efficiency of judicial systems: model definition and output estimation," Journal of Applied Economics, vol. 23, no. 1, pp. 385-408, 2020. 